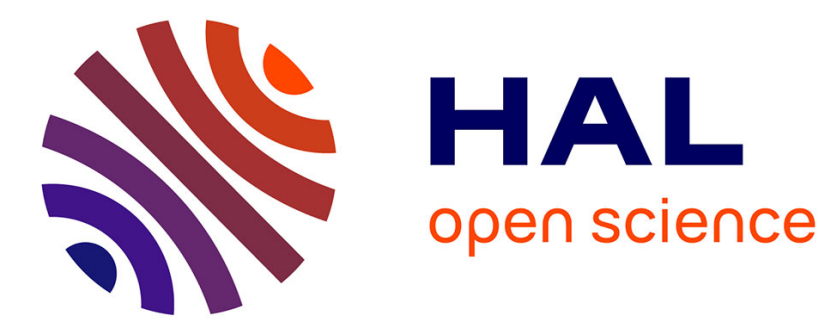

\title{
Isotope effects in electron-impact dissociation of $\mathrm{D} 2 \mathrm{H}+$
}

P Defrance, J J Jureta, J Lecointre, X Urbain

\section{To cite this version:}

P Defrance, J J Jureta, J Lecointre, X Urbain. Isotope effects in electron-impact dissociation of D2H+. Journal of Physics B: Atomic, Molecular and Optical Physics, 2011, 44 (7), pp.75202. 10.1088/09534075/44/7/075202 . hal-00608727

\section{HAL Id: hal-00608727 \\ https://hal.science/hal-00608727}

Submitted on 14 Jul 2011

HAL is a multi-disciplinary open access archive for the deposit and dissemination of scientific research documents, whether they are published or not. The documents may come from teaching and research institutions in France or abroad, or from public or private research centers.
L'archive ouverte pluridisciplinaire HAL, est destinée au dépôt et à la diffusion de documents scientifiques de niveau recherche, publiés ou non, émanant des établissements d'enseignement et de recherche français ou étrangers, des laboratoires publics ou privés. 


\title{
Isotope effects in electron-impact dissociation of $\mathbf{D}_{\mathbf{2}} \mathbf{H}^{+}$ \\ P. Defrance ${ }^{1}$, J. J. Jureta ${ }^{1,2}$, J. Lecointre ${ }^{1}$ and X. Urbain ${ }^{1}$
}

\author{
${ }^{1}$ Université Catholique de Louvain, Institute of Condensed Matter and Nanosciences, Chemin \\ du Cyclotron 2, B-1348 Louvain-la-Neuve, Belgium \\ ${ }^{2}$ Institute of Physics, University of Belgrade, P.O.Box 68, 11081, Belgrade, Serbia
}

\begin{abstract}
Absolute cross sections have been measured using the crossed electron-ion beams method for electron-impact dissociation of the $\mathrm{D}_{2} \mathrm{H}^{+}$molecular ion yielding $\mathrm{H}^{+}, \mathrm{D}^{+}, \mathrm{HD}^{+}$and $\mathrm{D}_{2}^{+}$ fragments. The collision energy ranges from a few eV up to $2.5 \mathrm{keV}$. Around the maximum, cross sections are found to be of similar amplitude: $(3.25 \pm 0.08) \times 10^{-17} \mathrm{~cm}^{2}$ for $\mathrm{H}^{+}$, $(3.56 \pm 0.15) \times 10^{-17} \mathrm{~cm}^{2}$ for $\mathrm{HD}^{+}$and $(3.33 \pm 0.11) \times 10^{-17} \mathrm{~cm}^{2}$ for $\mathrm{D}_{2}^{+}$; except for $\mathrm{D}^{+}$for which the maximum cross section is $(4.62 \pm 0.09) \times 10^{-17} \mathrm{~cm}^{2}$. Individual contributions for dissociative excitation and for dissociative ionization are determined for each product. Close analysis of present data brings into evidence isotope effects in the fragmentation pattern of the $\mathrm{D}_{2} \mathrm{H}^{+}$ target. Ejection of the lightest isotope is generally favored: for resonant dissociative excitation $\left(\mathrm{H}^{+}\right.$over $\left.\mathrm{D}^{+}\right)$, for dissociative excitation (molecular ions $\mathrm{D}_{2}^{+}$and $\mathrm{HD}^{+}$, associated with ejection of $\mathrm{H}$ and $\mathrm{D}$, respectively) and for dissociative ionization, but not for $\mathrm{H}^{+}$and $\mathrm{D}^{+}$ produced via dissociative excitation. Present dissociative excitation cross sections for $\mathrm{D}_{2} \mathrm{H}^{+}$ are found to be significantly lower than those measured for $\mathrm{D}_{3}^{+}$, although those of DI agree well together.
\end{abstract}

\section{PACS: 34-80, 52-20}

Key words: deuterium, hydrogen, isotope, molecular ion, electron-ion collision, ionization, excitation, dissociation, cross section.

\section{Introduction}

Dissociation of small polyatomic ions is an important process in the chemistry of planetary atmospheres, interstellar clouds [1] and various laboratory experiments [2]. Many deuterated molecules have been detected in the interstellar environment where the material is mainly in the molecular form. The observation of deuterated molecules appears to be easier than that of atomic deuterium itself. The cosmic ratio $[\mathrm{HD}] /\left[\mathrm{H}_{2}\right]$ is detected to be in the order of $10^{-5}$, 
which coincides with the expected value of the elemental $[\mathrm{D}] /[\mathrm{H}]$ ratio [3]. Polyatomic deuterated molecules are enhanced in deuterium in comparison to their hydrogenated counterparts and the isomeric ratio $[\mathrm{XD}] /[\mathrm{XH}]$ is found to be around $10^{-2}$. In warm interstellar regions, such the Orion bar, the cosmic ratio $\left[\mathrm{H}_{2} \mathrm{D}^{+}\right] /\left[\mathrm{H}_{3}^{+}\right]$is observed to be 0.02 . In cold dense regions, where gas-phase species are expected to accrete on dust grains, chemical fractionation occurs so $\mathrm{HD}$ efficiently reacts with $\mathrm{H}_{3}^{+}$to form $\mathrm{H}_{2} \mathrm{D}^{+}, \mathrm{D}_{2} \mathrm{H}^{+}$and $\mathrm{D}_{3}^{+}$[4]. Studies of interstellar chemistry including all isotopologues of $\mathrm{H}_{3}^{+}$predict that, in dense depleted regions, the abundance of $\mathrm{H}_{2} \mathrm{D}^{+}$is similar to that of $\mathrm{D}_{2} \mathrm{H}^{+}$and they also predict that $\mathrm{D}_{3}^{+}$is abundant [5].

Breakup dynamics and the isotope effect in the dissociation of $\mathrm{H}_{3}^{+}$and of $\mathrm{D}_{3}^{+}$have been theoretically studied by Strasser et al [6]. Because of the $\boldsymbol{D}_{3 \mathrm{~h}}$ symmetry, a small isotope effect is likely to be due to the difference in the width of the initial wave function for these two isotopologues. For $\mathrm{H}_{2} \mathrm{D}^{+}$and for $\mathrm{D}_{2} \mathrm{H}^{+}$, the $\boldsymbol{D}_{3 h}$ symmetry is broken and only the $\boldsymbol{C}_{2 v}$ symmetry remains. Based on the Born-Oppenheimer approximation, the potential energy surfaces of these heteronuclear targets $\left(\mathrm{H}_{2} \mathrm{D}^{+}\right.$and $\left.\mathrm{D}_{2} \mathrm{H}^{+}\right)$are identical to that of the homonuclear targets $\left(\mathrm{H}_{3}^{+}\right.$and $\left.\mathrm{D}_{3}^{+}\right)$. Rotational excitation of $\mathrm{H}_{2} \mathrm{D}^{+}$and of $\mathrm{D}_{2} \mathrm{H}^{+}$is lower than that of symmetric species because asymmetric isotopologues exhibit a non-vanishing permanent dipole moment (unlike $\mathrm{H}_{3}^{+}$and $\mathrm{D}_{3}^{+}$), so they can radiatively cool down and reduce both vibrational and rotational internal energies [7].

The experimental results of Strasser et al [7] give evidence for an enhanced occurrence of linear dissociation geometries in the dissociative recombination (DR) of $\mathrm{H}_{2} \mathrm{D}^{+}$and of $\mathrm{D}_{2} \mathrm{H}^{+}$, revealing isotope effects. For $\mathrm{H}_{2} \mathrm{D}^{+}$, the $\mathrm{D}$ atom dominantly lies between the two hydrogen atoms (H-D-H), while no preference for the linear $\mathrm{H}-\mathrm{H}-\mathrm{D}$ (or $\mathrm{D}-\mathrm{H}-\mathrm{H}$ ) geometry is observed. The situation is reversed for $\mathrm{D}_{2} \mathrm{H}^{+}$, in which case the linear D-D-H (or H-D-D) geometry is preferred compared to the linear D-H-D configuration. The force driving the breakup causes a larger acceleration when acting on the $\mathrm{H}$ atom than on the $\mathrm{D}$ atom. It influences the dissociation process by favoring the ejection of the lighter fragment. Weak enhancements of symmetric dissociation geometries were also found for $\mathrm{H}_{3}^{+}$and $\mathrm{D}_{3}^{+}$[6], but results were difficult to analyze because the three constituents are indistinguishable.

In the DR of $\mathrm{H}_{2} \mathrm{D}^{+}$, the relative fraction of the two two-body channels $\left(\mathrm{H}_{2}+\mathrm{D}\right.$ and $\mathrm{HD}+\mathrm{H})$ is constant over the whole energy range [8]. However, in the $\mathrm{DR}$ of $\mathrm{D}_{2} \mathrm{H}^{+}$, Buhr et al [9] have recently found that the two-body $\left(\mathrm{D}_{2}+\mathrm{H}\right.$ and $\left.\mathrm{HD}+\mathrm{D}\right)$ relative fraction is constant up 
to $0.2 \mathrm{eV}$ but it strongly changes in the $1-10 \mathrm{eV}$ energy range. The relative fraction $2\left(\mathrm{D}_{2}+\mathrm{H}\right) /(\mathrm{HD}+\mathrm{D})$ is expected to be 1 in the absence of any isotope effect, but it is measured to be $1.27 \pm 0.05$ at relative electron-ion energies around $0 \mathrm{eV}$ and it is found to increase to $3.7 \pm 0.5$ at about $5 \mathrm{eV}$. This large isotope effect implies that, in the $\mathrm{DR}$ of $\mathrm{D}_{2} \mathrm{H}^{+}$, the formation of $\mathrm{D}_{2}+\mathrm{H}$ is more favorable than that of HD+D. It appears that the general tendency in $\mathrm{DR}$ reactions is to favor ejection of the lightest fragments and to fractionate into the heaviest deuterated molecules.

Buhr et al [9] estimated the population distributions of the vibrational levels for the molecular fragments $\mathrm{D}_{2}(v)$ and $\mathrm{HD}(v)$. They were found to be similar for both channels and similar to the distributions obtained in the DR of $\mathrm{H}_{3}^{+}$and $\mathrm{D}_{3}^{+}[6]$. The deduced vibrational populations are wide, showing a bell-shape-like behavior (centered on $v=5-7$ ) covering all possible vibrational states up to $v=15$ or even $v=20$. For $\mathrm{D}_{2} \mathrm{H}^{+}$, only the vibrational states within the electronic ground state of the fragments are energetically accessible in both channels: the available final states are $\mathrm{D}_{2}\left(\mathrm{X}^{1} \Sigma_{\mathrm{g}}(v)\right)+\mathrm{H}(1 \mathrm{~s})$ with $v=0$ to 20 and $\mathrm{HD}\left(\mathrm{X}^{1} \Sigma_{\mathrm{g}}(v)\right)+\mathrm{D}(1 \mathrm{~s})$ with $v=0$ to 17 , respectively. The shape of the distribution is independent of the isotope and the shift in the position of the most populated quantum state reflects the different vibrational level spacing of the species. In contrast to homonuclear $\mathrm{H}_{3}^{+}$and $\mathrm{D}_{3}^{+}$, the heteronuclear $\mathrm{D}_{2} \mathrm{H}^{+}$should have lower internal excitation because the latter possesses an electrical dipole moment, allowing a much faster radiative decay of the rotational excitation. Diatomic fragments formed in electronically excited states are not expected to remain bound because of strong predissociation and because of radiative decay to the ${ }^{3} \Sigma_{\mathrm{u}}$ dissociative state. The decay of excited singlet and triplet states tends hence to contribute to three-body fragmentation.

Electron-impact experiments on deuterated molecular ions are currently performed in our laboratory by means of a crossed electron-ion beams set-up. Absolute cross sections and kinetic-energy-release distributions have been published for dissociation of the homonuclear $\mathrm{D}_{3}^{+}$target [10]. Results have been reported for formation of $\mathrm{D}^{+}$and $\mathrm{D}_{2}^{+}$ions, from their respective appearance thresholds up to $2.5 \mathrm{keV}$. For both fragments, an overall good agreement is observed in the energy region below $30 \mathrm{eV}$ between our results and those of storage ring facilities measured by Jensen et al [11] and by Le Padellec et al [12]. Appearance energies are measured to be $(4.5 \pm 0.5) \mathrm{eV}$ and $(6.0 \pm 0.5) \mathrm{eV}$ for $\mathrm{D}^{+}$and for $\mathrm{D}_{2}^{+}$respectively. For $\mathrm{D}^{+}$, the cross section displays a broad peak in the low electron energy range, which is attributed to resonant dissociative excitation (RDE). The threshold measured at $(14.0 \pm 1.0) \mathrm{eV}$ 
is in good agreement with the vertical excitation energy calculated for direct dissociative excitation [13]. For $\mathrm{D}_{2}^{+}$, no isolated RDE peak can be clearly observed and the non-zero cross section below the direct DE threshold reflects the width of the Franck-Condon region of the $\mathrm{D}_{3}^{+}$ground state. Dissociative excitation cross sections $\left(\sigma_{\mathrm{DE}}\right)$ as well as dissociative ionization cross sections $\left(\sigma_{\mathrm{DI}}\right)$ have been separately obtained for both fragments. Dissociative ionization thresholds are observed at $(11.0 \pm 0.5) \mathrm{eV}$ and at $(12.0 \pm 0.5) \mathrm{eV}$, for $\mathrm{D}^{+}$and $\mathrm{D}_{2}^{+}$ production, respectively. Both thresholds are observed to be analogous, around $11.5 \mathrm{eV}$, which is too low to be consistent with a Franck-Condon transition. A shoulder is discernible in the cross section at about $30 \mathrm{eV}$ and it is expected to correspond to the energy threshold of the DI process because it is close to the vertical ionization threshold of $\mathrm{H}_{3}^{+}(33.47 \mathrm{eV})$.

In order to obtain a more comprehensive understanding of the isotope effect on electron-ion collisions in the hydrogen family, we present here the experimental study of the electron-impact dissociation of the isotopologue $\mathrm{D}_{2} \mathrm{H}^{+}$. Results are reported for the production of the $\mathrm{H}^{+}, \mathrm{D}^{+}, \mathrm{HD}^{+}$and $\mathrm{D}_{2}^{+}$fragment ions. Dissociation of this heteronuclear molecular target proceeds via ten possible reaction channels:

$$
\begin{aligned}
\mathrm{D}_{2} \mathrm{H}^{+}+\mathrm{e}^{-} & \rightarrow \mathrm{H}^{+}+\mathrm{D}_{2}+\mathrm{e}^{-} \\
& \rightarrow \mathrm{H}^{+}+\mathrm{D}+\mathrm{D}+\mathrm{e}^{-} \\
& \rightarrow \mathrm{D}^{+}+\mathrm{HD}+\mathrm{e}^{-} \\
& \rightarrow \mathrm{D}^{+}+\mathrm{D}+\mathrm{H}+\mathrm{e}^{-} \\
& \rightarrow \mathrm{HD}^{+}+\mathrm{D}+\mathrm{e}^{-} \\
& \rightarrow \mathrm{D}_{2}^{+}+\mathrm{H}+\mathrm{e}^{-} \\
\mathrm{D}_{2} \mathrm{H}^{+}+\mathrm{e}^{-} & \rightarrow \mathrm{HD}^{+}+\mathrm{D}^{+}+2 \mathrm{e}^{-} \\
& \rightarrow \mathrm{H}^{+}+\mathrm{D}_{2}^{+}+2 \mathrm{e}^{-} \\
& \rightarrow \mathrm{H}^{+}+\mathrm{D}^{+}+\mathrm{D}+2 \mathrm{e}^{-} \\
& \rightarrow \mathrm{D}^{+}+\mathrm{D}^{+}+\mathrm{H}+2 \mathrm{e}^{-}
\end{aligned}
$$

Dissociative excitation (DE) processes are represented by reactions (1-6) and the dissociative ionization (DI) ones by reactions (7-10). In the present experiment, individual ionic fragments result from both DE and DI reactions. A specific procedure has been developed to separate the contributions and absolute cross sections are reported separately for $\mathrm{DE}$ and for DI, from their respective thresholds up to $2.5 \mathrm{keV}$ [14]. 


\section{Experimental method and apparatus}

The animated crossed electron-ion beams method is applied [15]. The molecular ion beam of well-defined energy (a few keV) interacts at right angles with the electron beam whose energy is tuned from a few electron volts up to $2.5 \mathrm{keV}$. Product ions are separated from the primary ion beam by using a double focusing $90^{\circ}$ magnetic analyzer. Product ions are further deflected by a $90^{\circ}$ electrostatic spherical deflector and directed onto the channeltron detector $[10]$.

The electron beam is swept across the ion beam in a linear motion at a constant speed $u$. The total number of events $K$ produced during one complete electron beam movement is related to the measured cross section $\sigma_{m}$ by

$$
\sigma_{m}=\frac{u K}{I_{e} I_{i} \gamma} \frac{v_{e} v_{i} q_{i} e^{2}}{\left(v_{e}^{2}+v_{i}^{2}\right)^{1 / 2}}
$$

In this expression, $\gamma$ is the detector efficiency, $I_{e}$ and $I_{i}, e$ and $q_{i} e, v_{e}$ and $v_{i}$, are the electron and ion beam current intensities, the charges and velocities of electrons and ions, respectively. Assuming $m_{i} \gg m_{e}$, the interaction energy $E(\mathrm{eV})$ is given by:

$$
E=V_{e}+\frac{m_{e}}{m_{i}}\left(q_{i} V_{i}-V_{e}\right)
$$

where $V_{e}$ and $V_{i}, m_{e}$ and $m_{i}$ are the acceleration voltages and masses of electrons and target ions, respectively.

Due to the transfer of internal potential energy, dissociation fragments exhibit both broad velocity and broad angular distribution in the laboratory frame. The angular acceptance of the magnet analyzer allows the total transmission of the angular distribution of product fragments emitted at a given velocity $v$ in the laboratory frame. In order to put the cross section on absolute scale, the velocity distribution is computed and the total cross section $\sigma$ is obtained by integrating this distribution over the entire velocity range.

The sum of the kinetic energy released to the dissociation fragments is represented by $E_{K E R}$. By assuming the fragmentation of the target to be binary only and by applying the momentum conservation, this sum is given by

$$
E_{\text {KER }}=\frac{m^{2} w^{2}}{2 \mu}
$$

where $w$ represents the fragment speed in the centre of mass frame. Ionic products basically form two velocity distributions whose shapes depend on the various $E_{K E R S}$ involved. At low energies, only DE is observed and the spectrum is narrow, which corresponds to low $E_{K E R s}$. 
Above the ionization threshold, the spectrum becomes broader because of the Coulomb repulsion experienced by DI fragments. For the $\mathrm{H}^{+}, \mathrm{D}^{+}, \mathrm{HD}^{+}$and $\mathrm{D}_{2}^{+}$fragments, the mean kinetic energies are measured to be 4.2, 4.7, 4.1 and $2.9 \mathrm{eV}$ and 9.2, 6.4, 8.6 and $8.3 \mathrm{eV}$, for DE and for DI, respectively. The maximum corresponding uncertainty is of $\pm 10 \%$. The DI signal is isolated by fitting the broader part of the spectrum. Absolute values of DE cross sections $\sigma_{\mathrm{DE}}$ are obtained by subtracting the DI contribution $\sigma_{\mathrm{DI}}$ from the total absolute cross section $\sigma$ for each fragment [14]. To help visualize dissociative contributions, corresponding cross sections are reproduced using linear combinations of the analytic expressions which are based upon a Bethe-Born form:

$$
\sigma(E)=a \times\left(1-\frac{E_{t h}}{E}\right)^{b} \times\left(\frac{1}{E}\right) \times \ln (e+c \times E)
$$

where $e$ is Euler's constant, $a, b$ and $c$ are fitting parameters and $E_{t h}$ is the threshold energy.

The total uncertainty (90\% confidence limit) for the absolute cross sections is estimated to be about $10 \%$, at maximum, and that associated to the electron energy is estimated to be $\pm 0.5 \mathrm{eV}[14]$.

\section{Results and discussion}

Absolute total cross sections for the production of $\mathrm{H}^{+}, \mathrm{D}^{+}, \mathrm{HD}^{+}$and $\mathrm{D}_{2}^{+}$are grouped in figure 1 (for clarity reasons, error bars are not systematically shown in this figure). Around the maximum, the cross sections for $\mathrm{H}^{+}, \mathrm{HD}^{+}$and $\mathrm{D}_{2}^{+}$are found to be of similar amplitude, whereas the maximum cross section for $\mathrm{D}^{+}$is found to be larger. The maximum total cross sections are measured to be $(3.25 \pm 0.08) \times 10^{-17} \mathrm{~cm}^{2}$ for $\mathrm{H}^{+},(3.56 \pm 0.15) \times 10^{-17} \mathrm{~cm}^{2}$ for $\mathrm{HD}^{+}$, $(3.33 \pm 0.11) \times 10^{-17} \mathrm{~cm}^{2}$ for $\mathrm{D}_{2}^{+}$and $(4.62 \pm 0.09) \times 10^{-17} \mathrm{~cm}^{2}$ for $\mathrm{D}^{+}$. In figures $2(\mathrm{a}-\mathrm{d})$, absolute total cross sections are presented individually for $\mathrm{H}^{+}, \mathrm{D}^{+}, \mathrm{HD}^{+}$and $\mathrm{D}_{2}^{+}$, respectively, together with their respective DE contributions while the DI contributions are presented separately in figure 2(e). Energy thresholds for dissociation of $\mathrm{H}_{3}^{+}$and of $\mathrm{D}_{2} \mathrm{H}^{+}$are listed in table 1 and absolute total cross sections are given in table 2, together with the associated total uncertainties. The following cross section ratios are presented in figure 2(f) in order to search for an apparent fingerprint of isotope effects: $2\left[\mathrm{H}^{+}+\mathrm{D}_{2}\right] /\left[\mathrm{D}^{+}+\mathrm{HD}\right]$ (DE for atomic ions), $2\left[\mathrm{D}_{2}^{+}\right.$ $+\mathrm{H}] /\left[\mathrm{HD}^{+}+\mathrm{D}\right]\left(\mathrm{DE}\right.$ for diatomic ions) and $2\left[\mathrm{D}_{2}^{+}+\mathrm{H}^{+}\right] /\left[\mathrm{HD}^{+}+\mathrm{D}^{+}\right](\mathrm{DI})$.

$\underline{\text { Figure } 1}$ and Table 1 


\section{1. $\mathrm{H}^{+}$channel}

Figure 2(a) shows the results for the formation of the $\mathrm{H}^{+}$fragment together with the $\mathrm{DE}$ contribution $\left(\mathrm{H}^{+}+\mathrm{D}_{2}\right.$, or $\left.\mathrm{H}^{+}+\mathrm{D}+\mathrm{D}\right)$. The DI contribution attributed to the $\mathrm{H}^{+}$channel is that of the $\mathrm{D}_{2}^{+}$fragment $\left(\mathrm{H}^{+}+\mathrm{D}_{2}^{+}+2 \mathrm{e}^{-}\right.$, reaction (8)). Because of unfavorable signal-to-noise ratio it has not been possible to obtain the DI contribution directly from the $\mathrm{H}^{+}$channel. The maximum DE cross section (reaction (1) or (2)) is measured to be $(1.98 \pm 0.15) \times 10^{-17} \mathrm{~cm}^{2}$ at 35 $\mathrm{eV}$, which is close to the maximum DI cross section $\left(\mathrm{H}^{+}+\mathrm{D}_{2}^{+}\right)$that is found to be $(2.13 \pm 0.06) \times 10^{-17} \mathrm{~cm}^{2}$ at $75 \mathrm{eV}$. For energies above $50 \mathrm{eV}$, the DI contribution is observed to be noticeably higher than that of DE.

The $\mathrm{H}^{+}$appearance energy at $(5.5 \pm 0.5) \mathrm{eV}$ fairly agrees with the energy threshold of reaction (1) $\left(\mathrm{H}^{+}+\mathrm{H}_{2}+\mathrm{e}^{-}, E_{t h}=4.4 \mathrm{eV}\right.$, Table 1) and with the experimental value of $(4.5 \pm 0.5) \mathrm{eV}$ determined for dissociative excitation of $\mathrm{D}_{3}^{+}$[10]. The cross section displays a broad peak in the region between 5 and $11 \mathrm{eV}$, centered on $8 \mathrm{eV}$, with a maximum value of $1.2 \times 10^{-17} \mathrm{~cm}^{2}$. The presence of this peak is attributed to resonant dissociative excitation (RDE) because it is observed below the threshold for direct dissociative excitation (DDE). Reaction (2) $\left(\mathrm{H}^{+}+\mathrm{D}+\mathrm{D}+\mathrm{e}^{-}, E_{t h}=8.9 \mathrm{eV}\right.$, Table 1) also contributes to $\mathrm{RDE}$ in the $\mathrm{H}^{+}$channel and its input is included in the present measurements. For a $\boldsymbol{C}_{2 \boldsymbol{v}}$ symmetry structure, the ${ }^{2} \mathrm{~A}^{1}$ excited electronic state of $\mathrm{H}_{3}$ (dissociation limit: $\mathrm{H}_{2}\left(\mathrm{X}^{1} \Sigma_{g}^{+}\right)+\mathrm{H}(\mathrm{n}=2)$ ) crosses the $\mathrm{X}^{1} \mathrm{~A}^{1}$ fundamental electronic state of $\mathrm{H}_{3}^{+}$(dissociation limit: $\mathrm{H}_{2}\left(\mathrm{X}^{1} \Sigma_{g}^{+}\right)+\mathrm{H}^{+}$) at $\mathrm{H}_{2}-\mathrm{H}$ bond distance of $2.6 a_{0}$ [16].

In the Franck-Condon region, the ${ }^{2} \mathrm{~A}^{1}$ potential energy surface of the excited $\mathrm{H}_{3}$ neutral lays about $6 \mathrm{eV}$ above that of the ground state of the $\mathrm{H}_{3}^{+}$ion $\left(\mathrm{X}^{1} \mathrm{~A}^{1}, v=0\right)$ [16]. The low experimental threshold for $\mathrm{H}^{+}$formation can be attributed to an initial capture of the electron into this excited state of $\mathrm{H}_{3}$ which autoionizes resulting in the dissociation into $\mathrm{H}_{2}+\mathrm{H}^{+}$ fragments. In addition to the vibrational population and to the resonant capture leading to the low RDE threshold, the large width of the Franck-Condon region associated with the excited vibrational levels must also be taken into account.

The cross section exhibits a second threshold at $(11.0 \pm 1.0) \mathrm{eV}$, which is pointed out by the change of slope at this energy. This result is observed to be below the vertical excitation energy calculated for the dissociative excitation of $\mathrm{H}_{3}^{+}$via the first excited triplet state $1^{3} \mathrm{E}^{\prime}$ at $14.75 \mathrm{eV}$ [13]. The signal measured for energies higher than this second threshold is attributed to non-resonant dissociative excitation. Excitation might also occur from excited 
vibrational levels populated within the $\mathrm{X}^{1} \mathrm{~A}_{1}^{\prime}$ ground state that would contribute to enlarge the Franck-Condon region and to lower the thresholds.

Table 2

\section{2. $\mathrm{D}^{+}$channel}

Figure 2(b) shows results for the formation of the $\mathrm{D}^{+}$fragment together with the $\mathrm{DE}$ contribution $\left(\mathrm{D}^{+}+\mathrm{HD}\right.$, or $\left.\mathrm{D}^{+}+\mathrm{D}+\mathrm{H}\right)$. As for $\mathrm{H}^{+}$, unfavorable signal-to-noise ratio prevented us from measuring directly the DI contribution for the $\mathrm{D}^{+}$channel so the DI contribution attributed to $\mathrm{D}^{+}$is actually that of $\mathrm{HD}^{+}\left(\mathrm{HD}^{+}+\mathrm{D}^{+}+2 \mathrm{e}^{-}\right.$, reaction (7)). The DI contribution is almost as broad as that of DE and the maximum DI cross section is found to be $(2.03 \pm 0.04) \times 10^{-17} \mathrm{~cm}^{2}$ at $75 \mathrm{eV}$. The DE contribution (reaction (3) or (4)), which is measured to be larger than that of DI over the whole energy range, is especially broad by comparison to the DE contributions measured for the three other fragments. It exhibits a plateau between 30 $\mathrm{eV}$ and $95 \mathrm{eV}$ and its maximum cross section is measured to be $(2.59 \pm 0.10) \times 10^{-17} \mathrm{~cm}^{2}$ at 75 $\mathrm{eV}$.

The $\mathrm{D}^{+}$appearance energy threshold that is measured to be $(10.5 \pm 0.5) \mathrm{eV}$ almost coincides with the direct $\mathrm{DE}$ threshold for $\mathrm{H}^{+}(11 \mathrm{eV})$, but it is $5 \mathrm{eV}$ above the corresponding RDE threshold for $(5.5 \mathrm{eV})$. It indicates that, for $\mathrm{D}_{2} \mathrm{H}^{+}$, no RDE contribution is detected in the $\mathrm{D}^{+}$channel, unlike what is observed for $\mathrm{H}^{+}$(within the experimental uncertainties). In the dissociation of $\mathrm{D}_{3}^{+}$leading to the $\mathrm{D}^{+}$product, a RDE contribution is apparent in the 4 to $12 \mathrm{eV}$ energy region [10]. There is a strong isotope effect in the dissociation of $\mathrm{D}_{2} \mathrm{H}^{+}$favoring the $\mathrm{H}^{+}$ channel over the $\mathrm{D}^{+}$channel in the low energy range below $10 \mathrm{eV}$. Firstly, the DE process yielding the $\mathrm{F}^{+}$fragment may occur via the capture of the incident electron into a $\mathrm{T}^{* *}$ doubly excited autoionizing dissociative state (resonant dissociative excitation, RDE):

$$
\mathrm{e}^{-}+\mathrm{T}^{+} \rightarrow \mathrm{T}^{* *} \rightarrow \mathrm{F}^{+}+\text {neutrals }+\mathrm{e}^{-}
$$

where the $\mathrm{T}^{* *}$ state is located just above the corresponding dissociation limit. $\mathrm{F}$ stands for fragment $\left(\mathrm{H}^{+}, \mathrm{H}_{2}^{+}\right.$and isotopologues $)$and $\mathrm{T}$ stands for target $\left(\mathrm{H}_{3}^{+}\right.$and isotopologues). Secondly, the DE process may occur via a direct transition to a $\mathrm{T}^{+*}(\mathrm{~d})$ dissociative excited state of the target (direct dissociation, DDE). Lastly, the DE process may also occur via a transition to a $\mathrm{T}^{+*(\mathrm{~b})}$ bound metastable excited state that is coupled with a $\mathrm{T}^{+*}{ }^{(\mathrm{d})}$ dissociative excited state (predissociation, PDE):

$$
\mathrm{e}^{-}+\mathrm{T}^{+} \rightarrow \mathrm{T}^{+*(\mathrm{~b})}+\mathrm{e}^{-} \rightarrow \mathrm{T}^{+*(\mathrm{~d})}+\mathrm{e}^{-} \rightarrow \mathrm{F}^{+}+\text {neutrals }+\mathrm{e}^{-}
$$


The peak observed below $10 \mathrm{eV}$ for $\mathrm{H}^{+}$is the signature of resonant dissociative excitation. As for predissociation, there is no evidence of its role in the present experiment, above $10 \mathrm{eV}$. The $\mathrm{D}^{+}$appearance energy $(10.5 \mathrm{eV})$ is observed to be lower than the direct $\mathrm{DE}$ threshold $\left(1^{3} \mathrm{E}^{\prime}, 14.75 \mathrm{eV}\right)$ but the shoulder that is merely discernible around $(15 \pm 1) \mathrm{eV}$ is expected to correspond to the energy threshold of the DE process. A plausible assumption for the observed energy threshold is that excitation occurs from excited vibrational levels populated within the ground state.

\section{3. $\mathrm{HD}^{+}$channel}

Figure 2(c) shows results for the formation of the $\mathrm{HD}^{+}$fragment together with the $\mathrm{DE}$ contribution $\left(\mathrm{HD}^{+}+\mathrm{D}\right)$. Experimental conditions were favorable enough to allow DE and DI contributions to be obtained separately for $\mathrm{HD}^{+}$[14]. Figure 2(e) shows results for the corresponding dissociative ionization contribution $\left(\mathrm{HD}^{+}+\mathrm{D}^{+}\right.$, reaction (7)). The $\mathrm{HD}^{+}$ appearance energy threshold is measured to be $(8.5 \pm 0.5) \mathrm{eV}$, which is higher than the expected one $\left(\mathrm{H}_{2}^{+}+\mathrm{H}+\mathrm{e}^{-}, E_{t \mathrm{~h}}=6.2 \mathrm{eV}\right)$. The DE contribution (reaction (5)) is measured to be noticeably higher than that of DI below $40 \mathrm{eV}$. The shape of the DE cross section is very sharp and its maximum is measured to be $(3.12 \pm 0.20) \times 10^{-17} \mathrm{~cm}^{2}$ at $14 \mathrm{eV}$.

The dissociative ionization threshold is observed around (15.0 \pm 1.0$) \mathrm{eV}$ and the maximum cross section is found to be $(2.03 \pm 0.04) \times 10^{-17} \mathrm{~cm}^{2}$ at $75 \mathrm{eV}$. Such energy is too low to be consistent with a threshold for a direct transition in the Franck-Condon (FC) region corresponding to a DI process and it is also too low to be attributed to the $\mathrm{H}^{+}+\mathrm{H}_{2}^{+}+2 \mathrm{e}^{-}$ reaction $\left(E_{t h}=19.8 \mathrm{eV}\right.$, Table 1). A distinctive shoulder is discernible at $(35.0 \pm 1.0) \mathrm{eV}$, which is expected to correspond to the energy threshold of the DI process. From a full configuration interaction calculation, Gorfinkiel and Tennyson [20] determined the vertical ionization threshold of $\mathrm{H}_{3}^{+}$to be $33.47 \mathrm{eV}$.

\section{4. $\mathrm{D}_{2}^{+}$channel}

Figure 2(d) shows results for the formation of the $\mathrm{D}_{2}^{+}$fragment together with the $\mathrm{DE}$ contribution $\left(\mathrm{D}_{2}^{+}+\mathrm{H}\right.$, reaction (6)) and the DI contribution $\left(\mathrm{H}^{+}+\mathrm{D}_{2}^{+}\right.$, reaction (8)) is presented in figure 2(e). As observed for $\mathrm{HD}^{+}$, the maximum of the cross section is reached for low electron energy, below $20 \mathrm{eV}$, and the DE contribution is measured to be higher than that of DI below $40 \mathrm{eV}$. The $\mathrm{D}_{2}^{+}$appearance energy threshold $(8.5 \pm 0.5 \mathrm{eV})$ is the same as that of 
$\mathrm{HD}^{+}$formation and the shape of the DE cross section is sharp as well, its maximum is measured to be $(2.99 \pm 0.10) \times 10^{-17} \mathrm{~cm}^{2}$ at $18 \mathrm{eV}$.

The threshold energy for the dissociative ionization process is observed to be $(18.0 \pm 1.0) \mathrm{eV}$ which is reasonably close to the predicted value $\left(\mathrm{H}^{+}+\mathrm{H}_{2}^{+}+2 \mathrm{e}^{-}, E_{t h}=19.8 \mathrm{eV}\right)$. The DI maximum cross section is found to be $(2.03 \pm 0.04) \times 10^{-17} \mathrm{~cm}^{2}$ at $75 \mathrm{eV}$. As it is the case for the $\mathrm{HD}^{+}$fragment, the DI threshold energy is inconsistent with the threshold for a direct transition in the Franck-Condon region $(33.47 \mathrm{eV})$. Nevertheless, a distinctive shoulder is also observed at $(35.0 \pm 1.0) \mathrm{eV}$, corresponding to the energy threshold of the direct DI process.

\section{Figure 2}

\subsection{Isotope effects within $\mathrm{D}_{2} \mathrm{H}^{+}$}

Deuterated molecules undergo chemical fragmentation that may enhance the relative abundance of isotopic fragments. The breakup dynamics and the isotope effects following dissociation of $\mathrm{D}_{2} \mathrm{H}^{+}$have been studied by analyzing the isotope ratios $2\left[\mathrm{H}^{+}+\mathrm{D}_{2}\right] /\left[\mathrm{D}^{+}+\mathrm{HD}\right]$, $2\left[\mathrm{D}_{2}^{+}+\mathrm{H}\right] /\left[\mathrm{HD}^{+}+\mathrm{D}\right]$ and $2\left[\mathrm{D}_{2}^{+}+\mathrm{H}^{+}\right] /\left[\mathrm{HD}^{+}+\mathrm{D}^{+}\right]$(Figure 2(f)). To study the isotope ratios within $\mathrm{D}_{2} \mathrm{H}^{+}$, we consider two-body dissociations only, for clarity reasons.

For DE yielding atomic ions, the ratio $2\left[\mathrm{H}^{+}+\mathrm{D}_{2}\right] /\left[\mathrm{D}^{+}+\mathrm{HD}\right]$ is measured to be $(0.9 \pm 0.1)$ on average in the $30-1000 \mathrm{eV}$ range. On a purely statistical ground, the $\mathrm{D}^{+}$channel should be twice as strong as the $\mathrm{H}^{+}$channel so the ratio $2\left[\mathrm{H}^{+}+\mathrm{D}_{2}\right] /\left[\mathrm{D}^{+}+\mathrm{HD}\right]$ should be equal to 1 . Present result indicates that there is no clear isotope effect above $30 \mathrm{eV}$. Carrington et al [17] studied the photodissociation of excited $\mathrm{D}_{2} \mathrm{H}^{+}$by recording $\mathrm{H}^{+}$and $\mathrm{D}^{+}$fragment separately. They observed that predissociation results in the formation of $\mathrm{H}^{+}$rather than $\mathrm{D}^{+}$because the ratio of corresponding signals was equal to three. This result was later corroborated by the theoretical predictions of Pollak and Schlier [18]. Conversely, Badenhoop et al [19] demonstrated that the $\mathrm{D}_{2} \mathrm{H}^{+}$ions formed from $\mathrm{D}_{2}^{+}(v=18,24)+\mathrm{H}_{2}$ tend to dissociate in favor of the $\mathrm{D}^{+}$channel. They also demonstrated that the centrifugal barrier for $\mathrm{D}_{2} \mathrm{H}^{+} \rightarrow \mathrm{D}^{+}+\mathrm{HD}$ would always be lower than that for $\mathrm{D}_{2} \mathrm{H}^{+} \rightarrow \mathrm{H}^{+}+\mathrm{D}_{2}$, resulting in the dissociation favoring $\mathrm{D}^{+}$ fragments. Present results do not support any of these predictions because the ratio of the cross sections $2\left[\mathrm{H}^{+}+\mathrm{D}_{2}\right] /\left[\mathrm{D}^{+}+\mathrm{HD}\right]$ is really close to 1 , so that no channel is promoted.

For DE yielding diatomic ions, the $\mathrm{D}_{2}^{+}$channel is clearly favored over the $\mathrm{HD}^{+}$one, underlining another unambiguous isotope effect. The ratio of the cross sections $2\left[\mathrm{D}_{2}^{+}\right.$ 
$+\mathrm{H}] /\left[\mathrm{HD}^{+}+\mathrm{D}\right]$ is measured to be $(2.8 \pm 0.4)$ on average in the $30-1000 \mathrm{eV}$ range. The isotope ratio of the DI cross sections $2\left[\mathrm{D}_{2}^{+}+\mathrm{H}^{+}\right] /\left[\mathrm{HD}^{+}+\mathrm{D}^{+}\right]$is observed to be almost constant in the $50-2500 \mathrm{eV}$, it is measured to be $(2.1 \pm 0.1)$ on average. It underlines that an isotope effect takes place above $50 \mathrm{eV}$, favoring the $\mathrm{D}_{2}^{+}$channel over the $\mathrm{HD}^{+}$channel. Statistically the $\mathrm{HD}^{+}+\mathrm{D}^{+}$channel is 2 times more favorable than the $\mathrm{D}_{2}^{+}+\mathrm{H}^{+}$channel. Therefore, if there were no isotope effect, the ratio $2\left[\mathrm{D}_{2}^{+}+\mathrm{H}^{+}\right] /\left[\mathrm{HD}^{+}+\mathrm{D}^{+}\right]$would be equal to 1 .

To review the study of the isotope effect in the dissociation of $\mathrm{D}_{2} \mathrm{H}^{+}$in the $50-2500$ $\mathrm{eV}$ range: the strongest isotope effect is observed for the dissociative excitation into the heavy ions $\left(2\left[\mathrm{D}_{2}^{+}+\mathrm{H}\right] /\left[\mathrm{HD}^{+}+\mathrm{D}\right]\right.$, about 3$)$, followed by dissociative ionization $\left(2\left[\mathrm{D}_{2}^{+}\right.\right.$ $\left.+\mathrm{H}^{+}\right] /\left[\mathrm{HD}^{+}+\mathrm{D}^{+}\right]$, about 2) and finally no isotope effect is observed for dissociative excitation into the light ions $\left(2\left[\mathrm{H}^{+}+\mathrm{D}_{2}\right] /\left[\mathrm{D}^{+}+\mathrm{HD}\right]\right.$, about 1$)$. In the low energy range (below $\left.10 \mathrm{eV}\right)$, a strong resonant process is observed for the $\mathrm{H}^{+}$channel only, indicating for a strong isotope effect favoring the $\mathrm{H}^{+}$channel over $\mathrm{D}^{+}$via $\mathrm{RDE}$ (see section 3.2).

For $\mathrm{H}_{3}^{+}$, Talbi and Saxon [21] have performed calculations on the $\boldsymbol{C}_{2 v}$ geometries (isosceles triangle) as well as on the $\boldsymbol{D}_{3 h}$ geometries (equilateral triangle). The electronic ground $\mathrm{X}^{1} \mathrm{~A}_{1}^{\prime}$ state is bound by $4.6 \mathrm{eV}$ with respect to $\mathrm{H}_{2}\left(\mathrm{X}^{1} \Sigma^{+}\right)+\mathrm{H}^{+}$(two-body asymptote) and by $9.3 \mathrm{eV}$ with respect to $\mathrm{H}(1 \mathrm{~s})+\mathrm{H}(1 \mathrm{~s})+\mathrm{H}^{+}$(three-body asymptote). The first excited state $1^{1} \mathrm{E}^{\prime}$ in $\boldsymbol{D}_{3 \boldsymbol{h}}$ geometry is degenerate and it splits in $2^{1} \mathrm{~A}^{\prime}$ and $3^{1} \mathrm{~A}^{\prime}$ in $\boldsymbol{C}_{2 v}$ geometry. The potential energy curve corresponding to the $2^{1} \mathrm{~A}^{\prime}$ state is very steep in the Franck-Condon region, it is the lowest one leading to $\mathrm{H}_{2}^{+}$with the dissociation limit $\mathrm{H}_{2}^{+}\left(\mathrm{X}^{2} \Sigma_{g}^{+}\right)+\mathrm{H}(2 \mathrm{~s})$. On the contrary, the curve associated to the $3{ }^{1} \mathrm{~A}^{\prime}$ state is almost flat and it corresponds to $\mathrm{H}^{+}$ formation $\left(\mathrm{H}_{2}^{*}+\mathrm{H}^{+}\right.$dissociation limit). Dissociation pathways are such that the potential energy decreases and approaches the minimum value associated with the dissociation limit, following the principle of minimum energy. The large steepness of the $2^{1} \mathrm{~A}^{\prime}$ state may explain for the relative importance of the $\left(\mathrm{D}_{2}^{+}+\mathrm{H}\right)$ channel and for the concomitant ejection of the lightest $\mathrm{H}$ fragment (reaction (6) dominating over reaction (5)). Considering the lightest fragment should be promoted, the $\left(\mathrm{H}^{+}+\mathrm{D}_{2}\right)$ channel (1) should take over the $\left(\mathrm{D}^{+}+\mathrm{HD}\right)$ channel (3) but the present isotope ratio is close to unity. It appears from theoretical studies that a large majority of the channels, both in $\boldsymbol{D}_{3 h}$ and $\boldsymbol{C}_{2 v}$ geometries, yields $\mathrm{H}^{+}$in a way or another, so it becomes difficult to assert which electronic state is more likely to take part in the dissociation process. Nevertheless, the fact that the $3^{1} \mathrm{~A}^{\prime}$ state is almost flat is coherent with 
the present observation. As for the ionization process, the corresponding potential energy curves are steep due to the Coulomb effect, so the ejection of the lightest fragment is promoted and $\left(\mathrm{D}_{2}^{+}+\mathrm{H}^{+}\right.$, reaction (8)) dominates over $\left(\mathrm{HD}^{+}+\mathrm{D}^{+}\right.$, reaction $\left.(7)\right)$, in agreement with the present observation.

This argument is supported by the classical potential scattering description [22]: the trajectory of a particle (mass $m$ ) in the field of a central potential $U(r)$ is confined to a plane and the total energy of the effective motion is a constant:

$$
E=\frac{1}{2} m\left(\frac{d r}{d t}\right)^{2}+U(r)+\frac{L^{2}}{2 m r^{2}}
$$

where $r$ is the position of the particle, $L$ is the angular momentum and the term $L^{2} / 2 m r^{2}$ corresponds to the centrifugal potential barrier. Equation (15) can be solved for

$$
\frac{d r}{d t}=\left[\frac{2}{m}\left(E-U(r)+\frac{L^{2}}{2 m r^{2}}\right)\right]^{1 / 2}
$$

This can be inverted and integrated over $r$, to give the time length $t$ of the motion:

$$
t=\sqrt{\frac{m}{2}} \int \frac{d r}{\sqrt{E-U(r)+L^{2} / 2 m r^{2}}}
$$

The motion is restricted to the allowed region determined by the range over which the argument of the square root is positive. For two isotopes particles (masses $m_{1}$ and $m_{2}$ ) performing the same path in the field of a given potential, it comes finally

$$
\frac{t_{2}}{t_{1}}=\sqrt{\frac{m_{2}}{m_{1}}}
$$

This purely classical reasoning indicates that, among isotopic species in the same kinematical conditions (potential and trajectory), the ejection of the lightest particle should be favored. This tendency is confirmed for $\mathrm{RDE}\left(\mathrm{H}^{+}\right.$over $\left.\mathrm{D}^{+}\right)$; for the $\mathrm{DE}$ diatomic ions $\mathrm{D}_{2}^{+}$and $\mathrm{HD}^{+}$, associated with ejection of $\mathrm{H}$ and $\mathrm{D}$, respectively and for $\mathrm{DI}$; but not for $\mathrm{H}^{+}$and $\mathrm{D}^{+}$ produced via DE.

$\underline{\text { Figure } 3}$

\section{6. $\mathrm{D}_{2} \mathrm{H}^{+}$versus $\mathrm{D}_{3}^{+}$fragmentation}

Total (DE+DI) absolute cross sections for electron-impact fragmentation of $\mathrm{D}_{2} \mathrm{H}^{+}$are compared with those obtained for the $\mathrm{D}_{3}^{+}$target [10], for the atomic and for the diatomic ions in figures 3(a) and 3(b), respectively. The total cross section for the atomic ions 
$\left(\mathrm{H}^{+}+\mathrm{D}^{+}\right) / \mathrm{D}_{2} \mathrm{H}^{+}$is the sum of the total cross sections for $\mathrm{H}^{+}$or $\mathrm{D}^{+}$formation and its maximum is measured to be $(7.8 \pm 0.2) \times 10^{-17} \mathrm{~cm}^{2}$ at $75 \mathrm{eV}$. It is almost a factor of two lower than the maximum cross section obtained for $\mathrm{D}^{+} / \mathrm{D}_{3}^{+},(13.9 \pm 1.1) \times 10^{-17} \mathrm{~cm}^{2}$ at $55 \mathrm{eV}$. Similarly to what is observed for DE (see below), it is clearly apparent that total cross sections for $\mathrm{D}_{2} \mathrm{H}^{+}$are found to be lower than those for $\mathrm{D}_{3}^{+}$, over the whole energy range. For the diatomic ions, the cross section for $\left(\mathrm{HD}^{+}+\mathrm{D}_{2}^{+}\right) / \mathrm{D}_{2} \mathrm{H}^{+}$is the sum of the total cross sections for $\mathrm{HD}^{+}$or $\mathrm{D}_{2}^{+}$ formation. Cross sections are observed to be lower by $20 \%$ than those for $D_{2}^{+} / D_{3}^{+}$, between $20 \mathrm{eV}$ to $100 \mathrm{eV}$, even so both sets of data agree well together in shape. In figure 3(c), for each target independently, we present the ratios of the total cross section for the light ions over those for the heavy ions. First, for the $D_{3}^{+}$target, the cross section ratio $\left[D^{+}\right] /\left[D_{2}^{+}\right]$is measured to be $1.9 \pm 0.2$. Then, for the $\mathrm{D}_{2} \mathrm{H}^{+}$target, the cross section ratio $\left[\mathrm{H}^{+}+\mathrm{D}^{+}\right] /\left[\mathrm{HD}^{+}+\mathrm{D}_{2}^{+}\right]$ is found to be $1.25 \pm 0.04$. Both ratios are higher than unity, which indicates that the production of light ions is dominant, whatever the target may be. This effect is even more pronounced for the $\mathrm{D}_{3}^{+}$target than for the $\mathrm{D}_{2} \mathrm{H}^{+}$one.

Results for electron-impact dissociation of $\mathrm{D}_{2} \mathrm{H}^{+}$are compared with those for the $\mathrm{D}_{3}^{+}$ target [10], for DE and DI separately. The DE contributions to atomic ions and to diatomic ions production are compared in figure 4(a) and 4(b), respectively. For DI, the cross sections for $\mathrm{D}_{3}^{+}$are compared with those for $\mathrm{D}_{2} \mathrm{H}^{+}$in figure $4(\mathrm{c})$. The corresponding cross section ratios $\left[X^{+} / \mathrm{D}_{3}^{+}\right] /\left[Y^{+} / \mathrm{D}_{2} \mathrm{H}^{+}\right]$are presented in figure $4(\mathrm{~d})$ in order to examine the behavior of the two isotopologues. $X^{+}$stands for the production of $\mathrm{D}^{+}$or $\mathrm{D}_{2}^{+}$(for the $\mathrm{D}_{3}^{+}$target), while $Y^{+}$ stands for the production of $\left(\mathrm{H}^{+}+\mathrm{D}^{+}\right)$or $\left(\mathrm{HD}^{+}+\mathrm{D}_{2}^{+}\right)$(for the $\mathrm{D}_{2} \mathrm{H}^{+}$target). The following cross section ratios have been estimated: $\left[\mathrm{D}^{+}\right] /\left[\mathrm{H}^{+}+\mathrm{D}^{+}\right]$(DE for atomic ions), $\left[\mathrm{D}_{2}^{+}\right] /\left[\mathrm{HD}^{+}+\mathrm{D}_{2}^{+}\right](\mathrm{DE}$ for diatomic ions) and $\left[\mathrm{D}_{2}^{+}\right] /\left[\mathrm{HD}^{+}+\mathrm{D}_{2}^{+}\right](\mathrm{DI})$.

The DE cross section for the atomic ions $\left(\mathrm{H}^{+}+\mathrm{D}^{+}\right) / \mathrm{D}_{2} \mathrm{H}^{+}$is the sum of the DE cross sections for $\mathrm{H}^{+}$or $\mathrm{D}^{+}$formation, its maximum is found to be $(4.3 \pm 0.2) \times 10^{-17} \mathrm{~cm}^{2}$ at $35 \mathrm{eV}$. It is a factor of two lower than what is obtained for $\mathrm{D}^{+} / \mathrm{D}_{3}^{+},(9.4 \pm 0.9) \times 10^{-17} \mathrm{~cm}^{2}$ at $55 \mathrm{eV}$. The cross sections for $\mathrm{D}_{2} \mathrm{H}^{+}$are found to be lower than those for $\mathrm{D}_{3}^{+}$over the whole energy range. For $\mathrm{D}_{2} \mathrm{H}^{+}$, the resonant contribution is noticeable below $10 \mathrm{eV}$, but much less pronounced than in the $\mathrm{D}_{3}^{+}$case because there is no RDE contribution in the $\mathrm{D}^{+}$formation from electronimpact dissociation of $\mathrm{D}_{2} \mathrm{H}^{+}$. In the $30-2500 \mathrm{eV}$ energy range, the ratio of the cross sections 
for the atomic ions $\left[\mathrm{D}^{+}\right] /\left[\mathrm{H}^{+}+\mathrm{D}^{+}\right]$is seen to exhibit the less regular behavior of all the calculated ratios. It is estimated to be $(2.7 \pm 0.4)$ on average. Irregularities affecting this ratio may be explained by the $\mathrm{D}^{+} / \mathrm{D}_{3}^{+}$cross sections that are affected by larger uncertainties than those for $\left(\mathrm{H}^{+}+\mathrm{D}^{+}\right) / \mathrm{D}_{2} \mathrm{H}^{+}$. The DE cross section for the diatomic ions $\left(\mathrm{HD}^{+}+\mathrm{D}_{2}^{+}\right) / \mathrm{D}_{2} \mathrm{H}^{+}$is the sum of the $\mathrm{DE}$ cross sections for $\mathrm{HD}^{+}$or $\mathrm{D}_{2}^{+}$formation. The $\left(\mathrm{HD}^{+}+\mathrm{D}_{2}^{+}\right) / \mathrm{D}_{2} \mathrm{H}^{+}$maximum cross section, $(5.9 \pm 0.2) \times 10^{-17} \mathrm{~cm}^{2}$ at $16 \mathrm{eV}$, is in reasonable agreement with the maximum cross section for $\mathrm{D}_{2}^{+} / \mathrm{D}_{3}^{+},(6.3 \pm 0.5) \times 10^{-17} \mathrm{~cm}^{2}$ at $18 \mathrm{eV}$, which is in opposition to what is observed for the atomic ions. Above the maximum, i.e. above $20 \mathrm{eV}$, the cross sections for $\mathrm{D}_{2} \mathrm{H}^{+}$are observed to be lower than those for $\mathrm{D}_{3}^{+}$. The ratio of the cross sections for the diatomic ions $\left[\mathrm{D}_{2}^{+}\right] /\left[\mathrm{HD}^{+}+\mathrm{D}_{2}^{+}\right]$is observed to be almost constant in the $15-2500 \mathrm{eV}$ range and it is found to be around (1.4 \pm 0.2$)$ on average. The DI cross section for $\mathrm{D}_{2} \mathrm{H}^{+}$is the sum of the DI cross sections for $\mathrm{HD}^{+}$or $\mathrm{D}_{2}^{+}$formation. Overall, the DI cross section for $\mathrm{D}_{2} \mathrm{H}^{+}$agrees very well with what is measured for $\mathrm{D}_{3}^{+}$. The corresponding maxima are $(4.16 \pm 0.05) \times 10^{-17}$ $\mathrm{cm}^{2}$ and $(4.3 \pm 0.2) \times 10^{-17} \mathrm{~cm}^{2}$ at $75 \mathrm{eV}$, for $\mathrm{D}_{2} \mathrm{H}^{+}$and $\mathrm{D}_{3}^{+}$, respectively. The ratio of the DI cross sections is found to be close to 1 over the whole energy range, it is measured to be $(1.07 \pm 0.05)$ on average.

To summarize the comparison between the $\mathrm{D}_{3}^{+}$and $\mathrm{D}_{2} \mathrm{H}^{+}$targets, the strongest isotope effect is observed for the dissociative excitation into the light ions $\left(\left[\mathrm{D}^{+}\right] /\left[\mathrm{H}^{+}+\mathrm{D}^{+}\right], 2.7\right)$, followed by dissociative excitation into the heavy ions $\left(\left[\mathrm{D}_{2}^{+}\right] /\left[\mathrm{HD}^{+}+\mathrm{D}_{2}^{+}\right], 1.4\right)$ and finally no effect is observed for dissociative ionization (isotope ratio close to 1).

The electronic potential energy curves are supposed to be identical for the $\mathrm{D}_{3}^{+}$and $\mathrm{D}_{2} \mathrm{H}^{+}$targets under the Born-Oppenheimer approximation and neglecting relativistic effects. But the vibrational and rotational manifolds are supposed to be different for each isotopologues, which corresponds to isotope effects. In the case of $\mathrm{D}_{2} \mathrm{H}^{+}$, the symmetry is broken because of the mass difference of the $\mathrm{H}$ and $\mathrm{D}$ nuclei. It causes the center of mass to shift away from the center of charge, creating a dipole moment, which is absent in the homonuclear molecules. Present sets of cross sections allow the quantification of the nonnegligible isotope effects for $\mathrm{D}_{2} \mathrm{H}^{+}$and $\mathrm{D}_{3}^{+}$which have to be related to these theoretical statements.

Figure 4 


\section{Conclusion}

Absolute cross sections for electron-impact dissociation of $\mathrm{D}_{2} \mathrm{H}^{+}$into $\mathrm{H}^{+}, \mathrm{D}^{+}, \mathrm{HD}^{+}$and $\mathrm{D}_{2}^{+}$ fragments have been measured in the energy region from their respective thresholds to 2.5 $\mathrm{keV}$ in the crossed electron-ion beams experiment. The present results for $\mathrm{D}_{2} \mathrm{H}^{+}$are compared with those measured for $\mathrm{D}_{3}^{+}[10]$. The analysis of the results brings into evidence significant isotope effects, which are supported by a purely classical reasoning. This reasoning indicates that, among isotopic species in identical kinematical conditions, the ejection of the lightest particle is favored. This tendency is first confirmed for the RDE process, which is observed in the low energy range $(5-11 \mathrm{eV})$ for $\mathrm{H}^{+} / \mathrm{D}_{2} \mathrm{H}^{+}$only and not for any of the other fragments. Moreover, its contribution is found to be much smaller than the $\mathrm{D}^{+} / \mathrm{D}_{3}^{+}$, observed in the previous experiment [10]. For DE, the tendency is confirmed for the molecular products $\mathrm{D}_{2}^{+}$ and $\mathrm{HD}^{+}$, associated with ejection of $\mathrm{H}$ and $\mathrm{D}$, respectively, but not for $\mathrm{H}^{+}$and $\mathrm{D}^{+}$which are found to be of the same importance. Finally, the ejection of the lightest particle is also evident for DI. Present DE cross sections for $\mathrm{D}_{2} \mathrm{H}^{+}$are found to be significantly lower than those measured for $\mathrm{D}_{3}^{+}$, although those for DI agree well together. Molecular dynamics treatments of these reactions should enlighten the present experimental results.

\section{Acknowledgements}

J. Lecointre acknowledges financial support provided by F.R.S.-FNRS (Belgium). X. Urbain is a Senior Research Associate of the F.R.S.-FNRS (Belgium). J. J. Jureta expresses his gratitude for the partial support of the project 141011 from the Ministry for Science and Technology of the Republic of Serbia. This work was supported by the Association EuratomBelgian State. We thank the Forschungszentrum Jülich for the lending of the ECR ion source and all the staff members of the IMCN for their assistance in this experiment.

\section{References}

[1] Geballe TR, McCall BJ, Hinkle KH and Oka T 1999 Astrophys. J. 510251

[2] Larsson M, Danared H, Mowat JR, Sigray P, Sundström G, Broström L, Filevich A, Källberg A, Mannervik S, Rensfelt KG and Datz S 1993 Phys. Rev. Lett. 70430

[3] Neufeld DA, Green JD, Hollenbach DJ, Sonnentrucker P, Melnick GJ, Bergin EA, Snell R L, Forrest WJ, Watson DM and Kaufman MJ 2006 Astrophys. J. 647 L33

[4] Roueff E and Gerin M 2003 Space Sci. Rev. 10661 
[5] Vastel C, Phillips TG and Yoshida H 2004 Astrophys. J. 606 L127

[6] Strasser D, Lammich L, Kreckel H, Krohn S, Lange M, Naaman A, Schwalm D, Wolf A and Zajfman D 2002 Phys. Rev. A 66032719

[7] Strasser D, Lammich L, Kreckel H, Lange M, Krohn S, Schwalm D, Wolf A and Zajfman

D 2004 Phys. Rev. A 69064702

[8] Datz S, Larsson M, Stromholm C, Sundstrom G, Zengin V, Danared H, Kallberg A, and af Ugglas M 1995 Phys. Rev. A 522901

[9] Buhr H, Mendes M B, Novotny O, Schwalm D, Berg MH, Bing D, Heber O, Krantz C, Orlov DA, Rappaport ML, Sorg T, Stutzel J, Varju J, Wolf A and Zajfman D 2010 Phys. Rev. A 81062702

[10] Lecointre J, Abdellahi El Ghazaly MO, Jureta JJ, Belic DS, Urbain X and Defrance P 2009 J. Phys. B: At. Mol. Opt. Phys. 42075201

[11] Jensen MJ, Pedersen HB, Safvan CP, Seiersen K, Urbain X and Andersen LH 2001 Phys. Rev A 63052701

[12] Le Padellec A, Larsson M, Danared H, Larson A, Peterson JR, Rosén S, Semaniak J and Strömholm C 1998 Phys. Scripta 57215

[13] Faure A and Tennyson J, 2002 J. Phys. B: At. Mol. Opt. Phys. 351865

[14] Lecointre J, Belic DS, Cherkani-Hassani H, Jureta JJ and Defrance P 2006 J. Phys. B: At. Mol. Opt. Phys. 393275

[15] Defrance P, Brouillard F, Claeys W and Van Wassenhove G 1981 J. Phys. B: At. Mol. Opt. Phys. 14103

[16] McCall BJ, Huneycutt AJ, Saykally RJ, Djuric N, Dunn GH, Semaniak J, Novotny O, Al-Khalili A, Ehlerding A, Hellberg F, Kalhori S, Neau A, Thomas R, Paal A, Osterdahl F and Larsson M 2004 Phys. Rev. A 70052716

[17] Carrington A, McNab I R and West Y D 1993 J. Chem. Phys. 981073

[18] Pollak E and Schlier C 1989 Acc Chem. Res. 22223

[19] Badenhoop J K, George C and Eaker C W 1987 J. Chem. Phys. 875317

[20] Gorfinkiel JD and Tennyson J 2005 J. Phys. B: At. Mol. Opt. Phys. 381607

[21] Talbi D and Saxon RP 1988 J. Chem. Phys. 892235

[22] Bransden BH and Joachain CJ 2003 Physics of Atoms and Molecules (2nd Edition, Pearson Education, Benjamin Cummings) ISBN: 978-0582356924

[23] NIST Chemistry WebBook, http://webbook.nist.gov/chemistry/ 
Figures and captions

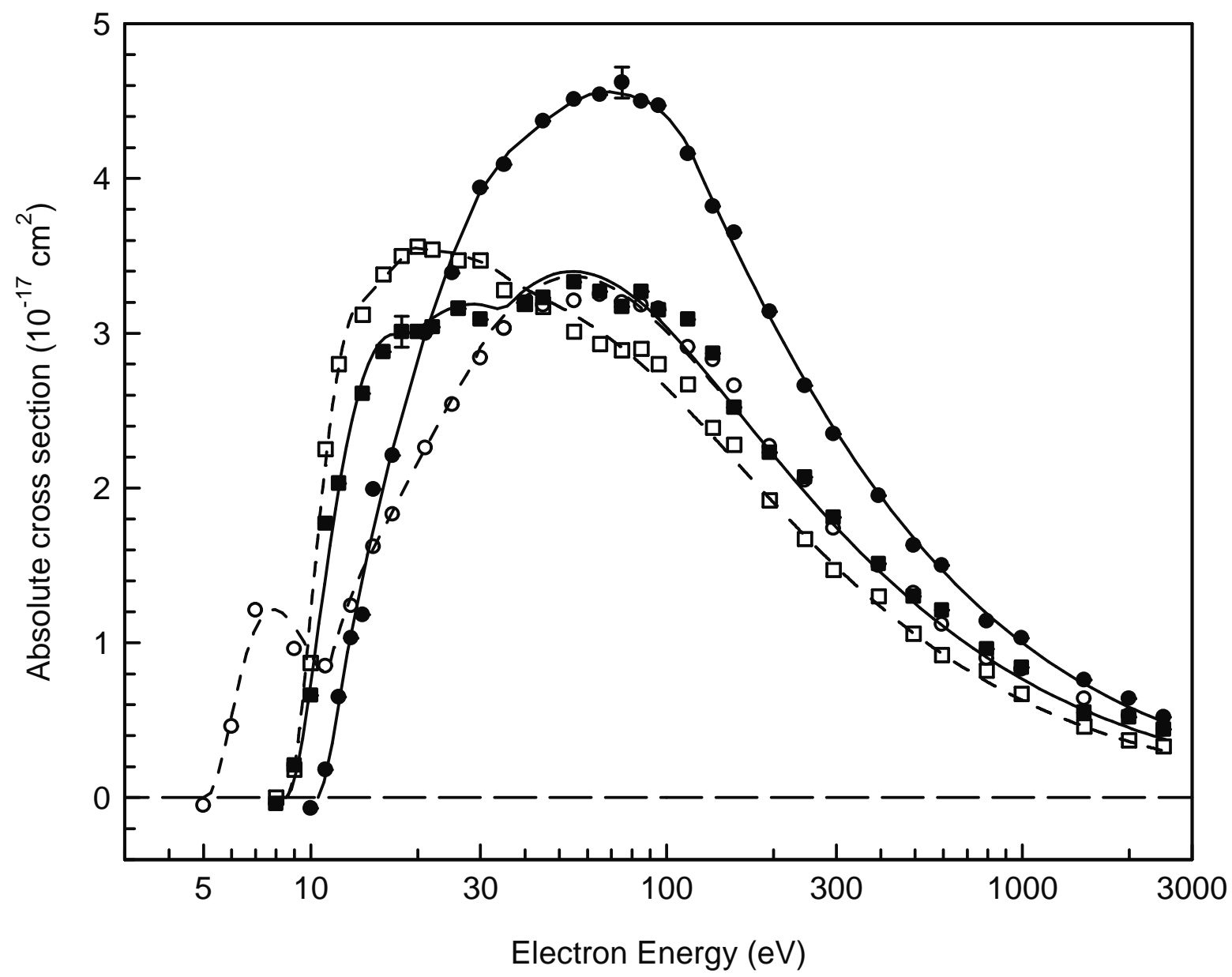

Figure 1. Absolute total cross sections for the fragmentation of $\mathrm{D}_{2} \mathrm{H}^{+}$leading to the production of $\mathrm{H}^{+}(\circ), \mathrm{D}^{+}(\bullet), \mathrm{HD}^{+}(\square)$ and $\mathrm{D}_{2}^{+}(\boldsymbol{\bullet})$ versus the electron energy. For clarity reasons, error bar are not presented in the figure. Solid and dashed lines are included to guide the eye. 

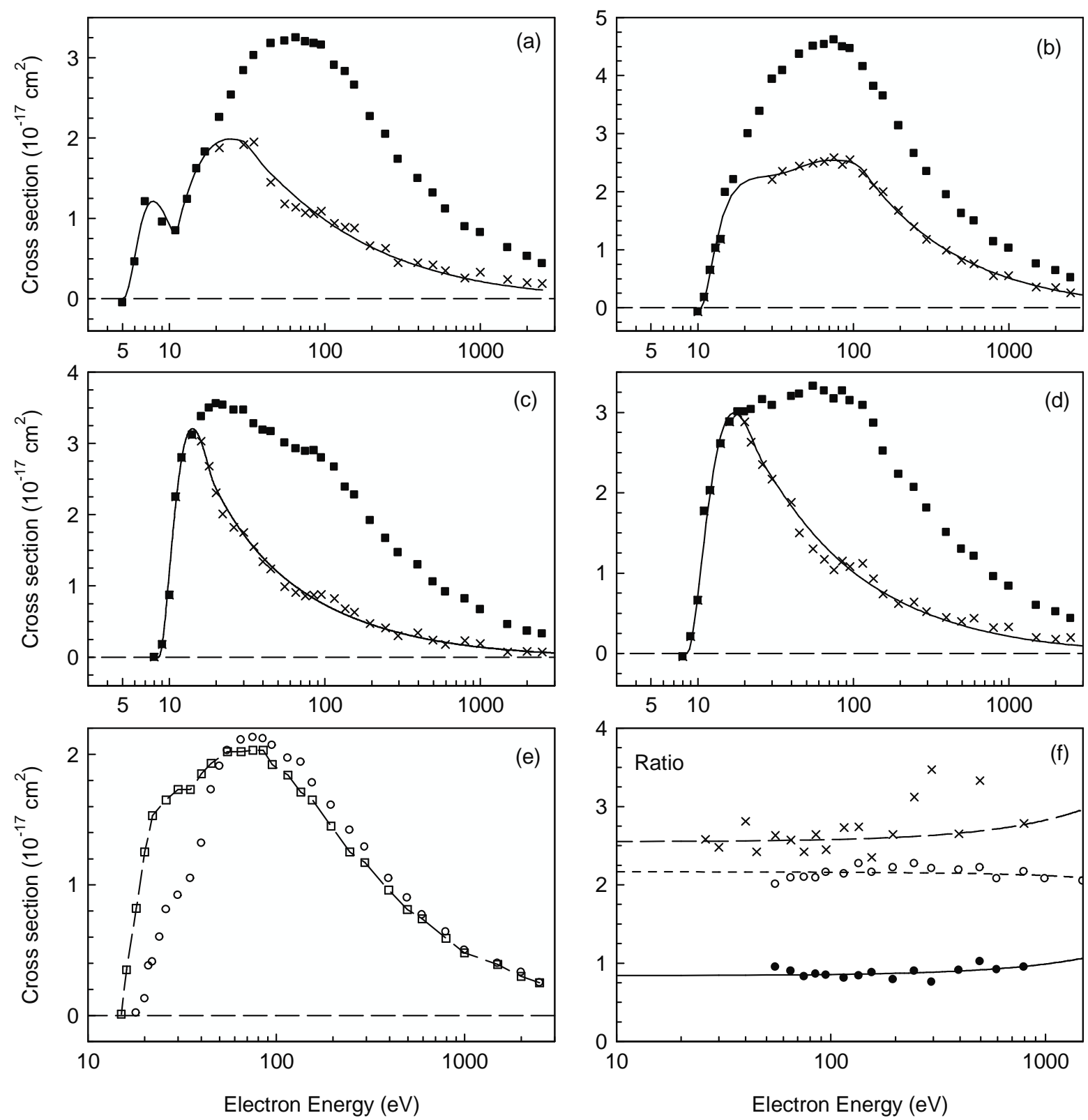

Figure 2. Absolute cross sections ( - ) for the fragmentation of $\mathrm{D}_{2} \mathrm{H}^{+}$leading to the production of (a) $\mathrm{H}^{+}$, (b) $\mathrm{D}^{+}$, (c) $\mathrm{DH}^{+}$and (d) $\mathrm{D}_{2}^{+}$versus the electron energy, together with the dissociative excitation (DE, $x$ ) contributions. The solid lines are a guide to the eye to help visualize DE contributions. The dissociative ionization (DI) is presented on panel (e) for the channel $\mathrm{HD}^{+}+\mathrm{D}^{+}(\square)$ and for the channel $\mathrm{D}_{2}^{+}+\mathrm{H}^{+}(\circ)$. Cross section ratios for the dissociative contributions are presented in panel (f): $2\left[\mathrm{H}^{+}+\mathrm{D}_{2}\right] /\left[\mathrm{D}^{+}+\mathrm{HD}\right](\mathrm{DE}, \bullet), 2\left[\mathrm{D}_{2}^{+}+\mathrm{H}\right] /\left[\mathrm{HD}^{+}+\mathrm{D}\right]$ $(\mathrm{DE}, \times)$ and $2\left[\mathrm{D}_{2}^{+}+\mathrm{H}^{+}\right] /\left[\mathrm{HD}^{+}+\mathrm{D}^{+}\right](\mathrm{DI}, \circ)$. See text for details. 

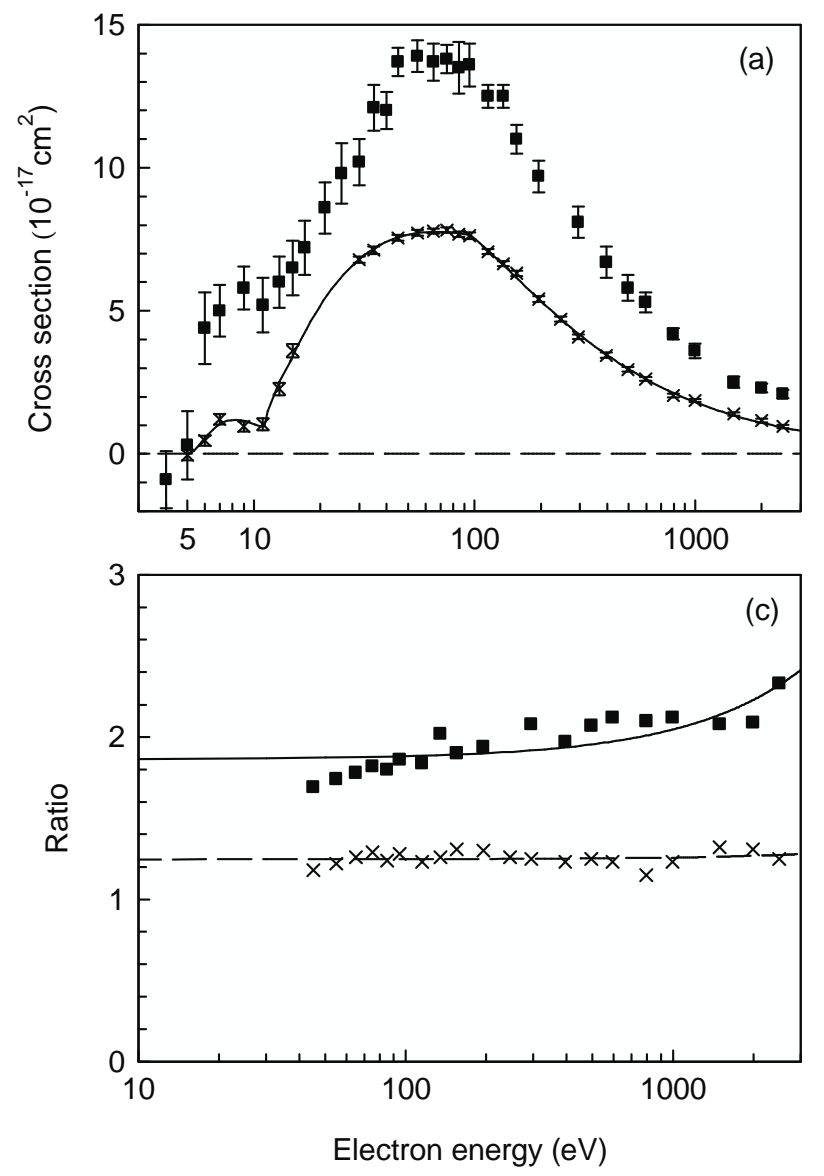

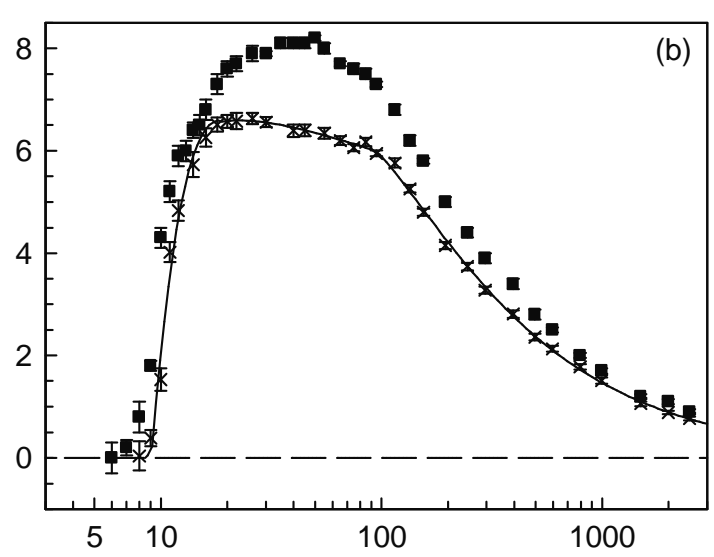

Electron energy $(\mathrm{eV})$

Figure 3. Absolute total cross sections (DE+DI) versus the electron energy

(a) for $\mathrm{D}^{+} / \mathrm{D}_{3}^{+}(\mathbf{m})$ and for $\left(\mathrm{H}^{+}+\mathrm{D}^{+}\right) / \mathrm{D}_{2} \mathrm{H}^{+}(\times)$,

(b) for $\mathrm{D}_{2}^{+} / \mathrm{D}_{3}^{+}(\boldsymbol{a})$ and for $\left(\mathrm{HD}^{+}+\mathrm{D}_{2}^{+}\right) / \mathrm{D}_{2} \mathrm{H}^{+}(\mathrm{x})$.

The solid line is a guide to the eye.

(c) Cross section ratio for $(\boldsymbol{a})$ the $\mathrm{D}_{3}^{+}$target $\left[\mathrm{D}^{+}\right] /\left[\mathrm{D}_{2}^{+}\right]$and for $(\mathrm{x})$ the $\mathrm{D}_{2} \mathrm{H}^{+}$target $\left[\mathrm{H}^{+}+\mathrm{D}^{+}\right] /\left[\mathrm{HD}^{+}+\mathrm{D}_{2}^{+}\right]$. See text for details. 

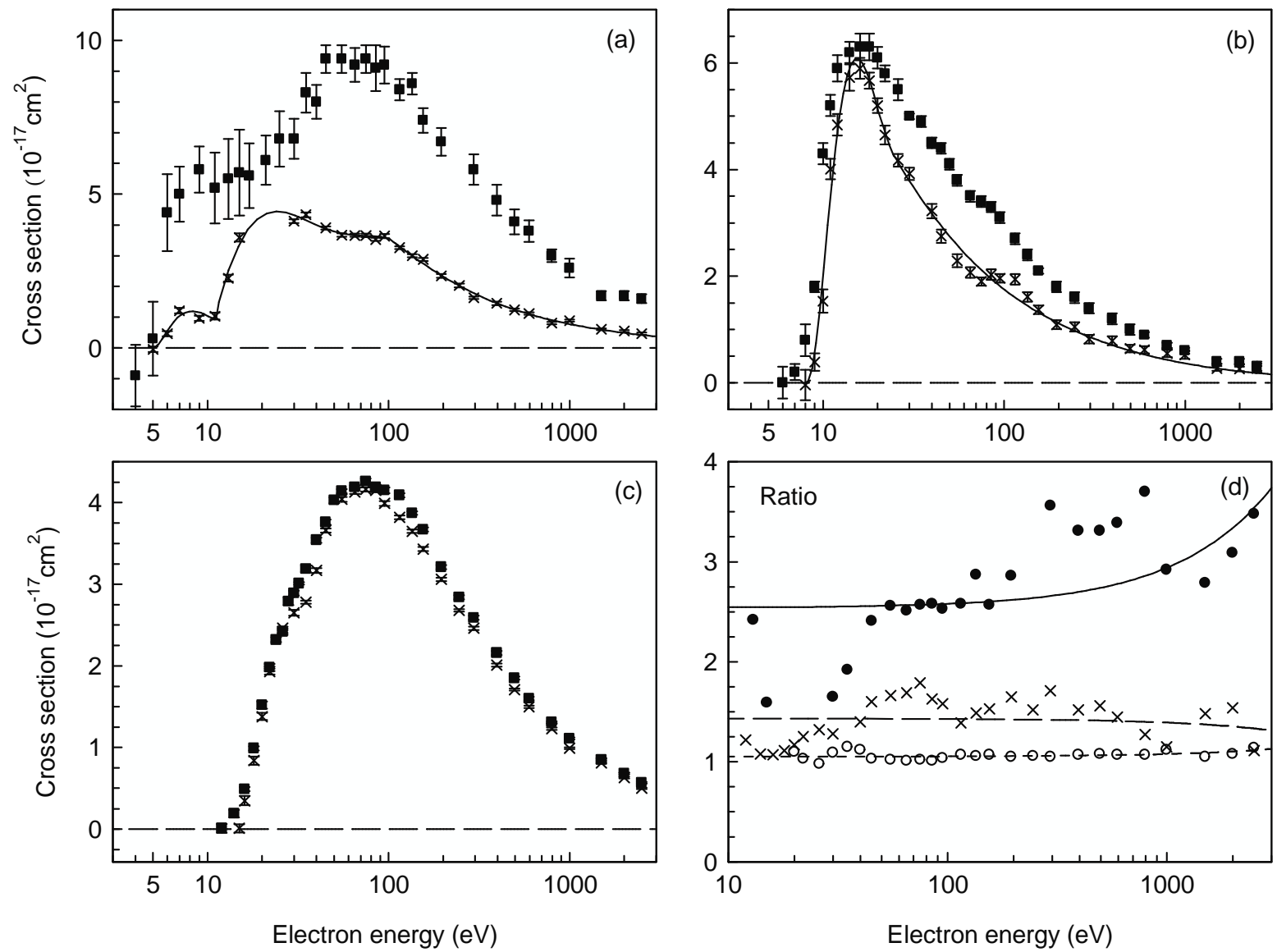

Figure 4. Absolute cross sections versus the electron energy for

(a) $\mathrm{DE}$ for $\mathrm{D}^{+} / \mathrm{D}_{3}^{+}(\boldsymbol{\square})$ and for $\left(\mathrm{H}^{+}+\mathrm{D}^{+}\right) / \mathrm{D}_{2} \mathrm{H}^{+}(\mathrm{x})$,

(b) $\mathrm{DE}$ for $\mathrm{D}_{2}^{+} / \mathrm{D}_{3}^{+}(\mathbf{m})$ and for $\left(\mathrm{HD}^{+}+\mathrm{D}_{2}^{+}\right) / \mathrm{D}_{2} \mathrm{H}^{+}(\times)$,

(c) DI for $\mathrm{D}_{2}^{+} / \mathrm{D}_{3}^{+}(\boldsymbol{\square})$ and for $\left(\mathrm{HD}^{+}+\mathrm{D}_{2}^{+}\right) / \mathrm{D}_{2} \mathrm{H}^{+}(\mathrm{x})$.

The solid line is a guide to the eye to help visualize DE contribution.

(d) Cross section ratio $\left[X^{+} / \mathrm{D}_{3}^{+}\right] /\left[\mathrm{Y}^{+} / \mathrm{D}_{2} \mathrm{H}^{+}\right]$for the dissociative contributions: $\left[\mathrm{D}^{+}\right] /\left[\mathrm{H}^{+}+\right.$ $\left.\mathrm{D}^{+}\right](\mathrm{DE}, \bullet),\left[\mathrm{D}_{2}^{+}\right] /\left[\mathrm{HD}^{+}+\mathrm{D}_{2}^{+}\right](\mathrm{DE}, \times)$ and $\left[\mathrm{D}_{2}^{+}\right] /\left[\mathrm{HD}^{+}+\mathrm{D}_{2}^{+}\right](\mathrm{DI}, \circ)$. See text for details. 


\begin{tabular}{|c|c|c|c|c|c|}
\hline $\begin{array}{l}\text { Dissociation } \\
\text { process }\end{array}$ & $\mathrm{H}_{3}^{+}$ & $\begin{array}{l}\text { Experimental } \\
(\mathrm{eV})^{1}\end{array}$ & $\begin{array}{l}\text { Predicted } \\
(\mathrm{eV})^{2}\end{array}$ & $\mathrm{D}_{2} \mathrm{H}^{+}$ & $\begin{array}{l}\text { Experimental } \\
(\mathrm{eV})\end{array}$ \\
\hline RDE & $\mathrm{H}^{+}+\mathrm{H}_{2}$ & $4.5 \pm 0.5$ & 4.4 & $\begin{array}{l}\mathrm{H}^{+}+\mathrm{D}_{2} \\
\mathrm{D}^{+}+\mathrm{HD}\end{array}$ & $\begin{array}{l}5.5 \pm 0.5 \\
\text { No }\end{array}$ \\
\hline $\begin{array}{l}\text { RIP } \\
\text { DE }\end{array}$ & $\begin{array}{l}\mathrm{H}^{+}+\mathrm{H}+\mathrm{H}^{-} \\
\mathrm{H}^{+}+\mathrm{H}+\mathrm{H}\end{array}$ & $14 \pm 1$ & $\begin{array}{l}8.1 \\
8.9 \\
14.75\left(1^{3} E^{\prime}\right)^{3}\end{array}$ & $\begin{array}{l}\mathrm{H}^{+}+\mathrm{D}+\mathrm{D} \\
\mathrm{D}^{+}+\mathrm{H}+\mathrm{D}\end{array}$ & $\begin{array}{l}11 \pm 1 \\
10.5 \pm 0.5 \\
15 \pm 1\end{array}$ \\
\hline $\begin{array}{l}\text { RIP } \\
\text { DE }\end{array}$ & $\begin{array}{l}\mathrm{H}_{2}^{+}+\mathrm{H}^{-} \\
\mathrm{H}_{2}^{+}+\mathrm{H}\end{array}$ & $6.0 \pm 0.5$ & $\begin{array}{l}5.8 \\
6.2\end{array}$ & $\begin{array}{l}\mathrm{HD}^{+}+\mathrm{D} \\
\mathrm{D}_{2}^{+}+\mathrm{H}\end{array}$ & $\begin{array}{l}8.5 \pm 0.5 \\
8.5 \pm 0.5\end{array}$ \\
\hline DI & $\mathrm{H}^{+}+\mathrm{H}_{2}^{+}$ & $\begin{array}{l}11.0 \pm 0.5 \\
12.0 \pm 0.5\end{array}$ & 19.8 & $\begin{array}{l}\mathrm{H}^{+}+\mathrm{D}_{2}^{+} \\
\mathrm{H}^{+}+\mathrm{D}^{+}+\mathrm{D}\end{array}$ & $18 \pm 1\left(\mathrm{D}_{2}^{+}\right)$ \\
\hline $\mathrm{DI}$ & $\mathrm{H}^{+}+\mathrm{H}^{+}+\mathrm{H}$ & & $\begin{array}{l}22.5 \\
33.47(\mathrm{FC})^{4}\end{array}$ & $\begin{array}{l}\mathrm{D}^{+}+\mathrm{HD}^{+} \\
\mathrm{D}^{+}+\mathrm{H}^{+}+\mathrm{D}\end{array}$ & $\begin{array}{l}15 \pm 1\left(\mathrm{HD}^{+}\right) \\
35 \pm 1\left(\mathrm{HD}^{+}\right) \\
35 \pm 1\left(\mathrm{D}_{2}^{+}\right)\end{array}$ \\
\hline
\end{tabular}

Table 1. Threshold energies (eV) for the dissociation of $\mathrm{H}_{3}^{+}$and of $\mathrm{D}_{2} \mathrm{H}^{+}$.

${ }^{1}[10]\left(\mathrm{D}_{3}^{+}\right.$target $),{ }^{2}[23],{ }^{3}[13],{ }^{4}[20]$

Note: RIP (Resonant-Ion-Pair formation) and FC (Franck-Condon) 
Table 2: Absolute total cross sections $\left(\mathrm{H}^{+}, \mathrm{D}^{+}, \mathrm{HD}^{+}\right.$and $\left.\mathrm{D}_{2}^{+}, 10^{-17} \mathrm{~cm}^{2}\right)$.

\begin{tabular}{|c|c|c|c|c|c|c|c|c|}
\hline & $\mathrm{H}^{+}$ & & $\mathrm{D}^{+}$ & & $\mathrm{HD}^{+}$ & & $\mathrm{D}_{2}^{+}$ & \\
\hline$E(e V)$ & $\sigma$ & $\Delta \sigma$ & $\sigma$ & $\Delta \sigma$ & $\sigma$ & $\Delta \sigma$ & $\sigma$ & $\Delta \sigma$ \\
\hline 5 & -0.05 & 0.18 & & & & & & \\
\hline 6 & 0.46 & 0.17 & & & & & & \\
\hline 7 & 1.21 & 0.18 & & & & & & \\
\hline 8 & & & & & 0.00 & 0.30 & -0.04 & 0.27 \\
\hline 9 & 0.96 & 0.17 & & & 0.18 & 0.26 & 0.21 & 0.06 \\
\hline 10 & & & -0.07 & 0.11 & 0.87 & 0.35 & 0.66 & 0.09 \\
\hline 11 & 0.85 & 0.20 & 0.18 & 0.23 & 2.25 & 0.17 & 1.77 & 0.22 \\
\hline 12 & & & 0.65 & 0.17 & 2.80 & 0.26 & 2.03 & 0.14 \\
\hline 13 & 1.24 & 0.22 & 1.03 & 0.23 & & & & \\
\hline 14 & & & 1.18 & 0.24 & 3.12 & 0.20 & 2.61 & 0.29 \\
\hline 15 & 1.62 & 0.20 & 1.99 & 0.27 & & & & \\
\hline 16 & & & & & 3.38 & 0.18 & 2.88 & 0.18 \\
\hline 17 & 1.83 & 0.13 & 2.21 & 0.09 & & & & \\
\hline 18 & & & & & 3.50 & 0.18 & 3.01 & 0.10 \\
\hline 20 & & & & & 3.56 & 0.15 & 3.01 & 0.10 \\
\hline 21 & 2.26 & 0.12 & 3.00 & 0.16 & & & & \\
\hline 22 & & & & & 3.54 & 0.16 & 3.04 & 0.15 \\
\hline 25 & 2.54 & 0.15 & 3.39 & 0.09 & & & & \\
\hline 26 & & & & & 3.47 & 0.12 & 3.16 & 0.09 \\
\hline 30 & 2.84 & 0.11 & 3.94 & 0.11 & 3.47 & 0.12 & 3.09 & 0.08 \\
\hline 35 & 3.03 & 0.13 & 4.09 & 0.15 & 3.28 & 0.07 & & \\
\hline 40 & & & & & 3.19 & 0.12 & 3.20 & 0.12 \\
\hline 45 & 3.18 & 0.09 & 4.37 & 0.10 & 3.17 & 0.11 & 3.23 & 0.11 \\
\hline 55 & 3.21 & 0.12 & 4.51 & 0.08 & 3.01 & 0.10 & 3.33 & 0.11 \\
\hline 65 & 3.25 & 0.08 & 4.54 & 0.09 & 2.93 & 0.08 & 3.27 & 0.09 \\
\hline 75 & 3.20 & 0.11 & 4.62 & 0.09 & 2.89 & 0.08 & 3.17 & 0.06 \\
\hline 85 & 3.18 & 0.10 & 4.50 & 0.09 & 2.90 & 0.09 & 3.27 & 0.08 \\
\hline 95 & 3.16 & 0.06 & 4.47 & 0.16 & 2.80 & 0.08 & 3.15 & 0.04 \\
\hline 115 & 2.91 & 0.05 & 3.82 & 0.09 & 2.67 & 0.10 & 3.09 & 0.08 \\
\hline 135 & 2.83 & 0.08 & 3.65 & 0.09 & 2.39 & 0.07 & 2.87 & 0.08 \\
\hline 155 & 2.66 & 0.09 & 3.56 & 0.11 & 2.28 & 0.08 & 2.52 & 0.06 \\
\hline 195 & 2.27 & 0.08 & 3.14 & 0.12 & 1.92 & 0.06 & 2.23 & 0.08 \\
\hline 245 & 2.05 & 0.06 & 2.66 & 0.13 & 1.67 & 0.08 & 2.07 & 0.06 \\
\hline 295 & 1.74 & 0.07 & 2.35 & 0.09 & 1.47 & 0.08 & 1.81 & 0.06 \\
\hline 395 & 1.50 & 0.08 & 1.95 & 0.10 & 1.30 & 0.08 & 1.51 & 0.07 \\
\hline 495 & 1.32 & 0.07 & 1.63 & 0.09 & 1.06 & 0.07 & 1.30 & 0.05 \\
\hline 595 & 1.12 & 0.05 & 1.50 & 0.08 & 0.92 & 0.04 & 1.21 & 0.07 \\
\hline 795 & 0.90 & 0.06 & 1.14 & 0.08 & 0.82 & 0.06 & 0.96 & 0.05 \\
\hline 995 & 0.83 & 0.04 & 1.03 & 0.06 & 0.67 & 0.06 & 0.84 & 0.06 \\
\hline 1495 & 0.64 & 0.06 & 0.76 & 0.05 & 0.46 & 0.05 & 0.55 & 0.04 \\
\hline 1995 & 0.53 & 0.06 & 0.64 & 0.06 & 0.37 & 0.04 & 0.52 & 0.03 \\
\hline 2495 & 0.44 & 0.06 & 0.52 & 0.06 & 0.33 & 0.03 & 0.44 & 0.04 \\
\hline
\end{tabular}

